\title{
The Relationship between Urban Surface Indices and Heat Islands in High and Low Building Areas
}

\author{
SAKAKIBARA Yasushi* and NARITA Goshin** \\ * Faculty of Education, Shinshu University; Nagano 380-8544, Japan. ** Jonan Elementary School; Suwa, Nagano 392-0022, Japan. \\ E-mail:ysakaki@shinshu-u.ac.jp
}

Received December 11, 2007; Accepted December 28, 2009

\begin{abstract}
During 2003, temperature distributions were observed 69 times in two types of residential areas in Imaihara, Nagano Prefecture, Japan. Both high and low building areas were warmer than the rural area at night. But a cool island appeared only in the high building area in the daytime. The maximum nocturnal heat island intensity occurred not at a calm condition but at the wind speed of about $1 \mathrm{~m} / \mathrm{s}$. In addition the wind speed in which the maximum heat island occurred in the high building area was larger than that in the low building area. The urban surface indices of the high and low building areas showed only small differences in the sky view factor and building/ land ratio but large differences in the floor-area ratio. Floor area ratio related to heat island formation in this area.
\end{abstract}

Key words floor-area ratio, heat island, urban climate, wind speed

\section{Introduction}

The urban heat island (UHI) appears clearly on calm clear nights (Oke 1987). The temperature cools greatly after sunset in rural areas. Since the downward long wave radiation from the buildings which blocks the sky view in urban areas becomes large, the loss of net long wave radiation at the urban street creates a small change. Thus the sky view factor (SVF) was regarded as one of the important parameters in nocturnal heat island formation. Oke (1981) showed the clear linear relation between SVF and urban-rural model temperature difference with a physical scale model experiment and the same relation between the SVF on the downtown street and the maximum UHI intensity with field observations in many cities.

The existence of buildings in urban areas played an active part in heat island formation. There are many factors, such as the larger heat capacity of building constituent materials, anthropogenic heat released from the buildings, the reduction of SVF on urban facets, the large roughness of urban surface and so on.

There are some reports about a numerical study of heat island. Kusaka and Kimura (2004a, 2004b) conducted sensitivity experiments to compare the affects on the surface temperature in the urban area using a two dimensional meso scale model with a single layer urban canopy model. They used anthropogenic heat, heat capacity, SVF and so on as an urban parameter. Martilli (2002) investigated urban influence on boundary structure using a meso scale model with an urban effect. These reports were conducted to study how different factors affected heat island formation in a virtual city under ideal meteorological conditions.

Tokairin et al. (2006) pointed out that the formation of the turbulent mixing due to the buildings and the drop of wind speed played an important part in a nocturnal urban heat island formation by comparing the results of a canopy model in 23 wards in Tokyo with the result of a field study in summer.

The turbulence structure of the nocturnal urban boundary layer was observed in Sapporo by Uno et al. (1988). They concluded that the mechanism of the nocturnal urban boundary layer formation was found to be controlled by the downward transport of sensible heat from elevated inversion which was caused by mechanically-generated turbulence.

Ohashi et al. (2007) demonstrated that the validation of the model results was not always enough because 1) as a result of the heterogeneity of urban temperature distribution a large number of temperature measurements were required for comparison with the model simulation and 2) it was difficult to measure directly the influence of waste heat from air conditioners under the urban thermal environment.

The heat capacity of a building and a city can not be 
measured easily, either. The urban canopy indices which are vegetation index, building/land ratio, floor-area ratio, and SVF value are measured and calculated. There are some reports between UHI intensity and these factors (ex. SVF, Oke (1981), Park (1987); area ratio of land use, Fukuoka (1983)). The correlation between UHI intensity and individual parameter can be seen in each report. But there was apparently no report which discussed parameters synthetically using field survey data.

In this study, temperature distributions in and around a high building area and a low building area were observed and the urban canopy indices were measured. We analyzed the relation between them and UHI intensity.

\section{Research site}

The study focussed on the Imaihara area south of the city of Nagano, Nagano Prefecture, Japan (Figure 1). In particular, we examined the Imai housing estate (population 2,000) that had been developed amongst numerous orchards and paddies to the northeast. While the estate could not be regarded as an isolated settlement, its building heights differ from those of neighboring low building residential areas. The area has low traffic density, especially at night. At the time of study, Imai had 19 residential buildings and two assembly buildings. The residential buildings were 4 to 14 stories tall (Figure 1). Because the buildings in Imai were higher than those in its environs, we designated this area as the high building area. In contrast, study points 5,7 , and 9 to the east of Imai where 2- to 3 -story buildings dominated were deemed the low building area. Sites 11-17, 34, and 35, comprised mainly of orchards or paddies, were chosen as rural sites. Finally, we regarded points $1-4,10,18-21$, and $31-33$, which were located at the boundary between different land uses, and points 6,36 , and 37 , located on a higher traffic-density road, as "other" areas.

\section{Methods}

\section{Observations}

Heat island observation points were selected at approximately $100-\mathrm{m}$ intervals (Figure 1 ). We travelled to predetermined observation points by car; Figure 1 shows the order of observations.

Temperatures were measured with a thermistor probe (9021-01; Hioki E.E. Corporation, Ueda, Japan) that was connected to a handheld computer in the car. The sensor had an accuracy of within $\pm 0.2^{\circ} \mathrm{C}$ and a time constant of approximately 300 seconds without ventilation. However, because the car moved at $10 \mathrm{~m} / \mathrm{s}$ during measurements, the sensor was ventilated. At this speed, the time constant was within 10 seconds. Observation data were recorded in the computer and then transferred to a desktop computer through a RS232C cable after each observation.

The thermistor probe was fixed in a radiation shield tube comprised of a polyvinyl chloride cylindrical pipe with diameter, thickness, and length of 107, 3, and $3600 \mathrm{~mm}$, respectively. The radiation shield was a pipe covered with an aluminium sheet to prevent a temperature increase caused by radiation. This radiation shield was connected to a polyvinyl chloride cylindrical pipe, $80 \mathrm{~mm}$ in diameter and $3200 \mathrm{~mm}$ in length, using a connector. The pipe was fixed on the top of the roof luggage carrier of the automobile, thus setting the radiation shield $1.5 \mathrm{~m}$ above the ground over the fender of the automobile. This position was the location least likely to receive engine heat (Sahashi 1983). Because observations were conducted while driving at a constant speed, no ventilation device was needed.

We travelled through 37 points in the numeral order shown in Figure 1. The traverse route was about $8 \mathrm{~km}$ in length and took approximately 40 minutes to complete. Time corrections were conducted at mid-observational time. The Imai housing estate and its environs are located in an area free from local topographic factors.

Temperature distributions were observed 69 times on days without precipitation from 14 January 2003 to 24 December 2003 (Table 1). Residential and rural area roads were partially covered by snow from January to March. Paddies were flooded from June to August and drained in September; rice was harvested in October.

\section{Representative wind direction and wind speed in this area}

Wind direction and wind speed were observed at the Shinonoi observatory at the Nagano Health Center located $2 \mathrm{~km}$ south of the observation area (Figure 1, symbol $\diamond)$. The anemometer was set above the roof at approximately $20 \mathrm{~m}$ above the ground.

\section{Vegetation index, building land ratio, and floor-area ratio}

The building/land ratio was defined as the proportion of the building area to the lot area. We calculated the building/land ratio of $250-\mathrm{m}$ squares at the center of observation points using a personal computer and image scanner. The floor-area ratio was defined as the proportion of the entire floor area of the building to the lot area. We calculated the floor-area ratio of 250$\mathrm{m}$ squares surrounding the central observation point 

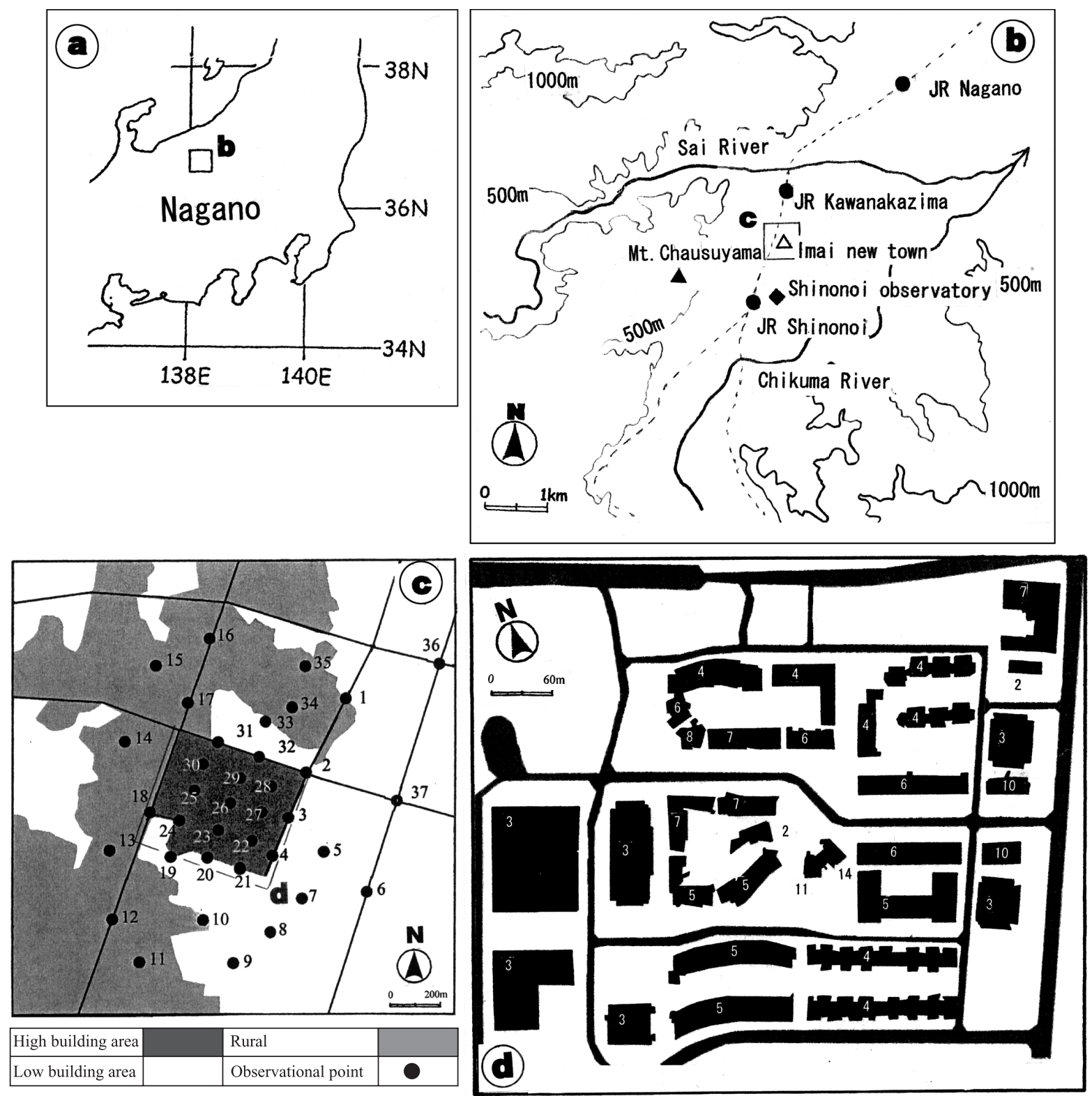

Figure 1. Location of the study area.

Numbers in Figure $1 \mathrm{~d}$ denote the number of floors in each building.

(Figure 2). The entire floor area was then calculated as the floor area multiplied by the number of stories, assuming that each floor had the same shape. The vegetation index was determined by the proportion of the lot area to vegetated areas (including fields, paddies, and orchards) surrounding the central observation point.

\section{Sky view factor}

The SVF was measured using a camera (F90X, Nikon, Tokyo, Japan) and a fisheye lens (fisheye-NIKKOR 8 mm F2.8; Nikon). We fixed the camera on the tripod. The shooting points were the same as the observational points. To determine SVF, we inserted a film negative in a slide mount and projected the image on a wall using a slide projector. We then affixed a chart for calculating
SVF (Itoh 1976) on the wall. The chart was divided into 500 blocks at the same projection area. We counted the number $(n)$ of blocks corresponding to the sky using the projection image on the chart. The SVF was then calculated as follows:

$$
\mathrm{SVF}=n \times 0.002
$$

\section{Average Temperature Anomalies and Altitudes of Observation Points}

The average temperature was determined for each observation. We calculated the temperature anomaly at each point using the average temperature for each point. We classified the observational days as cloudy nights, 
Table 1. Meteorological conditions on observational dates

\begin{tabular}{|c|c|c|c|c|c|c|c|}
\hline \multirow[b]{2}{*}{ No } & \multirow[b]{2}{*}{ Date } & \multirow[b]{2}{*}{ Time } & \multirow{2}{*}{ 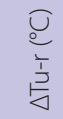 } & \multirow{2}{*}{$\begin{array}{l}\frac{\bar{O}}{U} \\
\frac{0}{U}\end{array}$} & \multicolumn{3}{|c|}{ Shinonoi observatory } \\
\hline & & & & & Hour & $\mathrm{m} / \mathrm{s}$ & Wind Ori. \\
\hline 1 & 030114 & $2155-2222$ & 0.6 & 9 & 22 & 0.8 & E \\
\hline 2 & 030116 & $1155-1220$ & 1.3 & 4 & 12 & 0.7 & SE \\
\hline 3 & 030117 & $1308-1339$ & 1.8 & 3 & 13 & 2.5 & ENE \\
\hline 4 & 030117 & $2151-2222$ & 1.4 & 4 & 22 & 1.3 & SSW \\
\hline 5 & 030121 & $2200-2225$ & 1.2 & 5 & 22 & 0.8 & NE \\
\hline 6 & 030130 & $2154-2226$ & 1.7 & 0 & 22 & 0.1 & C \\
\hline 7 & 030206 & $2149-2218$ & 1.3 & 0 & 22 & 0.8 & SSW \\
\hline 8 & 030228 & $1325-1346$ & 1.8 & 0 & 13 & 1.9 & ENE \\
\hline 9 & 030228 & $2145-2206$ & 1.2 & 0 & 22 & 0.9 & E \\
\hline 10 & 030311 & $2152-2215$ & 0.5 & 2 & 22 & 2 & WNW \\
\hline 11 & 030313 & $1219-1248$ & 2.7 & 3 & 12 & 3.7 & ENE \\
\hline 12 & 030313 & 2150-2209 & 1.1 & 2 & 22 & 1.3 & E \\
\hline 13 & 030314 & $2204-2224$ & 0.9 & 9 & 22 & 0.2 & C \\
\hline 14 & 030324 & $2204-2223$ & 1.1 & 10 & 22 & 1.4 & NNE \\
\hline 15 & 030325 & $2157-2217$ & 0.4 & 3 & 22 & 2.5 & NE \\
\hline 16 & 030326 & $2138-2201$ & 1.5 & 2 & 22 & 1.4 & SSW \\
\hline 17 & 030327 & $2142-2201$ & 1.0 & 2 & 22 & 2.2 & WNW \\
\hline 18 & 030401 & 2153-2213 & 1.1 & 1 & 22 & 1.4 & SW \\
\hline 19 & 030410 & $2146-2207$ & 1.5 & 0 & 22 & 0.7 & NW \\
\hline 20 & 030415 & 2143-2203 & 0.8 & 9 & 22 & 3.8 & SW \\
\hline 21 & 030418 & $2151-2210$ & 2.5 & 9 & 22 & 0.2 & C \\
\hline 22 & 030421 & $2151-2214$ & 0.6 & 6 & 22 & 1.5 & NE \\
\hline 23 & 030422 & $2152-2216$ & 0.7 & 5 & 22 & 3.3 & WSW \\
\hline 24 & 030428 & $2151-2211$ & 2.1 & 0 & 22 & 0.4 & C \\
\hline 25 & 030503 & $2201-2220$ & 2.1 & 0 & 22 & 1.1 & $\mathrm{~N}$ \\
\hline 26 & 030506 & $2209-2231$ & 0.5 & 2 & 22 & 4.6 & SW \\
\hline 27 & 030510 & $2208-2229$ & *0.8 & 3 & 22 & 1.5 & SSW \\
\hline 28 & 030526 & $2156-2218$ & 0.4 & 3 & 22 & 4.1 & SW \\
\hline 29 & 030528 & $2220-2242$ & 2.5 & 6 & 22 & 1 & ESE \\
\hline 30 & 030604 & $2200-2221$ & 1.6 & 1 & 22 & 0.3 & C \\
\hline 31 & 030605 & $2206-2224$ & 2.3 & 1 & 22 & 0.5 & NNW \\
\hline 32 & 030606 & $2127-2147$ & 1.8 & 9 & 22 & 0.5 & SSE \\
\hline 33 & 030608 & $2145-2206$ & 3.0 & 3 & 22 & 1.4 & SW \\
\hline 34 & 030609 & 2134-2154 & 0.7 & 3 & 22 & 4.9 & SW \\
\hline 35 & 030630 & $2232-2254$ & 1.3 & 3 & 22 & 0.2 & C \\
\hline
\end{tabular}

\begin{tabular}{|c|c|c|c|c|c|c|c|}
\hline \multirow[b]{2}{*}{ No } & \multirow[b]{2}{*}{ Date } & \multirow[b]{2}{*}{ Time } & \multirow{2}{*}{$\frac{0}{0}$} & \multirow{2}{*}{$\frac{\bar{\partial}}{\frac{\partial}{U}}$} & \multicolumn{3}{|c|}{ Shinonoi observatory } \\
\hline & & & & & Hour & $\mathrm{m} / \mathrm{s}$ & Wind Ori \\
\hline 36 & 030702 & $2202-2220$ & 1.4 & 6 & 22 & 0.2 & C \\
\hline 37 & 030704 & $2213-2237$ & 0.7 & 9 & 22 & 5.4 & ENE \\
\hline 38 & 030719 & $2153-2212$ & 0.6 & 3 & 22 & 4 & SW \\
\hline 39 & 030726 & $2208-2229$ & 0.6 & 9 & 22 & 1.7 & ENE \\
\hline 40 & 030802 & $2216-2238$ & 0.9 & 2 & 22 & 1.4 & E \\
\hline 41 & 030810 & $2223-2241$ & 0.7 & 9 & 22 & 0.6 & NNE \\
\hline 42 & 030813 & $2240-2300$ & 0.7 & 6 & 23 & 3.9 & WSW \\
\hline 43 & 030815 & $2254-2314$ & ${ }^{*} 0.6$ & 9 & 23 & 3.7 & SW \\
\hline 44 & 030824 & $2240-2301$ & 1.5 & 4 & 23 & 0.8 & SSW \\
\hline 45 & 030827 & $2244-2303$ & 1.5 & 9 & 23 & 2.6 & SW \\
\hline 46 & 030908 & $2210-2231$ & 1.5 & 1 & 22 & 3.4 & WSW \\
\hline 47 & 030910 & $2208-2229$ & 1.1 & 7 & 22 & 1.4 & $\mathrm{~N}$ \\
\hline 48 & 030917 & $2155-2215$ & 2.2 & 6 & 22 & 0.7 & $\mathrm{~N}$ \\
\hline 49 & 030918 & $2148-2207$ & 1.4 & 9 & 22 & 0.5 & NNW \\
\hline 50 & 030927 & $2154-2213$ & * 1.0 & 7 & 22 & 1.2 & NNE \\
\hline 51 & 030928 & $2159-2219$ & 1.0 & 6 & 22 & 1 & NE \\
\hline 52 & 031002 & $2222-2241$ & 1.4 & 1 & 22 & 1.2 & NE \\
\hline 53 & 031006 & $2144-2211$ & 2.2 & 4 & 22 & 0.2 & C \\
\hline 54 & 031015 & $2148-2210$ & 1.7 & 1 & 22 & 0.7 & ENE \\
\hline 55 & 031027 & $1226-1246$ & 1.3 & 3 & 12 & 1.7 & SW \\
\hline 56 & 031027 & $2136-2156$ & 0.9 & 1 & 22 & 4.5 & WSW \\
\hline 57 & 031029 & $1244-1302$ & 1.3 & 1 & 13 & 7.3 & ENE \\
\hline 58 & 031029 & $2155-2217$ & 2.2 & 0 & 22 & 0.6 & NNW \\
\hline 59 & 031030 & $1249-1309$ & 0.9 & 0 & 13 & 4.6 & ENE \\
\hline 60 & 031102 & $2151-2213$ & 2.9 & 0 & 22 & 0.7 & ESE \\
\hline 61 & 031104 & $2154-2216$ & 1.3 & 3 & 22 & 4.8 & WSW \\
\hline 62 & 031105 & $1244-1310$ & 0.6 & 10 & 13 & 2.2 & ENE \\
\hline 63 & 031116 & $2134-2153$ & 0.6 & 3 & 22 & 3.4 & $\mathrm{NE}$ \\
\hline 64 & 031122 & $2151-2212$ & 1.7 & 1 & 22 & 0.8 & NNW \\
\hline 65 & 031128 & $2154-2215$ & 0.3 & 5 & 22 & 4.8 & SW \\
\hline 66 & 031203 & $2155-2217$ & 1.3 & 3 & 22 & 2.8 & N \\
\hline 67 & 031223 & $1303-1328$ & 1.7 & 0 & 13 & 0.5 & ENE \\
\hline 68 & 031223 & $2145-2207$ & 2.5 & 1 & 22 & 0.2 & C \\
\hline 69 & 031224 & $1243-1310$ & 2.0 & 1 & 13 & 1.1 & ENE \\
\hline
\end{tabular}

The "*" symbol denotes a data set that is lacking in data.

fine nights and fine days. After removing observations with missing data, our data set contained 45 runs for fine nights, 11 runs for cloudy nights, and 10 runs for fine days. We defined fine days for this study as daytime with fine and clear weather.

Figure 3 shows the average temperature anomaly and standard deviation at each point. The horizontal axis denotes the distance from point 1 . Symbols $\square, \square, \bigcirc$, and - represent high building, low building, rural, and mixed land use, respectively. The horizontal bar shows the standard deviation of the temperature anomaly, and the dotted line denotes the altitude of points. Since the altitude difference among points was about $3 \mathrm{~m}$, it was unnecessary to correct by the height difference. No large 


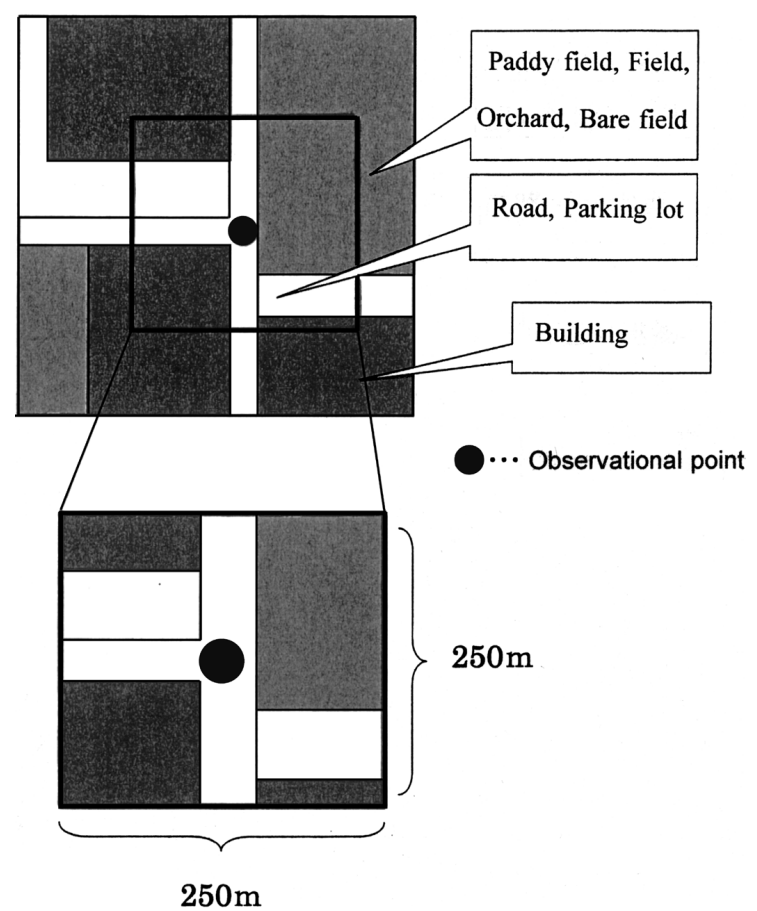

Figure 2. Outline of land use around the observational points.

differences between fine nights and cloudy nights were found. The average temperature anomaly for the high building area was higher than that for other areas at night; however, the average temperature anomaly in the high building area was lower than that of the other areas in the daytime. The average temperature anomalies at points 6 , 36 , and 37 were higher than those of other areas for days and nights, a pattern that can likely be explained by these areas having the highest traffic densities.

\section{Horizontal Temperature Distributions}

Figure 4 shows the horizontal temperature distributions during a distinct heat island occurrence. At that time, there was a $1.4 \mathrm{~m} / \mathrm{s}$ southwest wind, and the cloud amount was 3 . There was a warm zone around points 27 and 28 within the Imai housing estate, and the UHI intensity was $3.0^{\circ} \mathrm{C}$. We selected 29 cases with cloud amounts of $0-0.8$ and wind speed less than $1.5 \mathrm{~m} / \mathrm{s}$ to study heat islands on clear, calm nights. The average temperature distribution pattern (not shown) was similar to that in Figure 4.

Next, we examined the average temperature distribution on cloudy, calm nights. We selected seven cases with cloud amounts of $0.9-1$ and wind speeds less than $1.5 \mathrm{~m} / \mathrm{s}$. The pattern (not shown) was similar to that in Figure 4 but the urban-rural temperature difference was smaller than that on clear, calm nights.

Figure 5 shows the average temperature distribution on nine fine days with cloud amounts of $0-0.8$. A cold
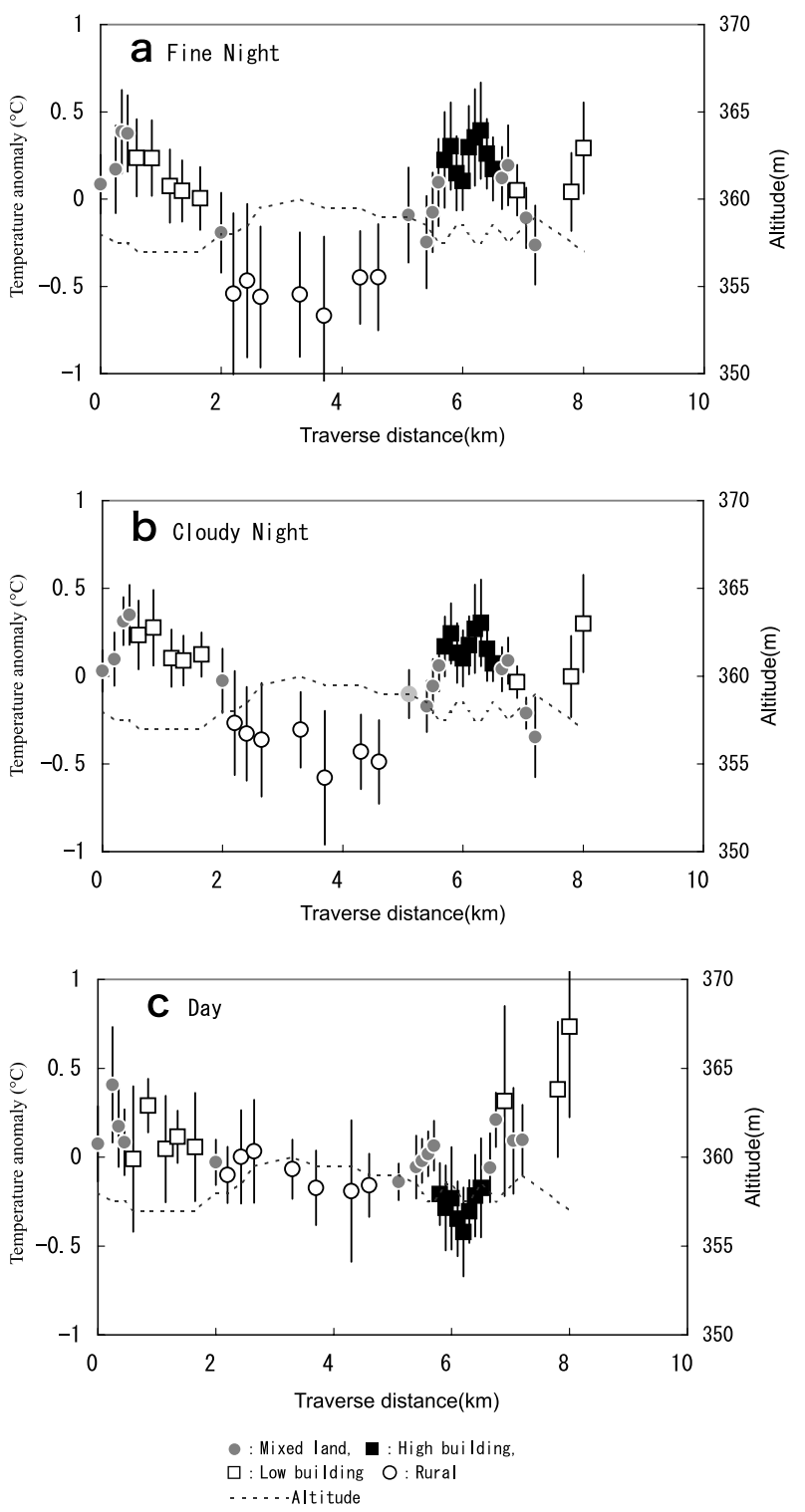

Figure 3. Mean temperature anomalies and altitudes in the traverse order.

: Mixed land, $\mathbf{\square}$ : High building area, $\square$ : Low building area, $\bigcirc$ : Rural area, -----: Altitude.

zone was found near point 27 within the Imai housing estate. Warm zones were located around points 6,36 , and 37; this feature may have been caused by the heavy road traffic and vehicle exhaust heat.

\section{Urban Heat Island Intensity and Wind Speed}

We compared the average temperature differences between high building and rural areas, $\Delta \mathrm{Th}-\mathrm{r}$, and those between low building and rural areas, $\Delta \mathrm{Tl}-\mathrm{r}$, on fine nights with wind speeds less than $1.5 \mathrm{~m} / \mathrm{s}$ (31 cases) and cloudy nights with wind speeds less than $1.5 \mathrm{~m} / \mathrm{s}$ (seven cases). On fine nights, the $\Delta$ Th-r value of $0.9^{\circ} \mathrm{C}$ exceeded the $\Delta \mathrm{Tl}-\mathrm{r}$ value of $0.7^{\circ} \mathrm{C}$ on fine, calm nights. However, $\Delta$ Th-r and $\Delta \mathrm{Tl}-\mathrm{r}$ both equalled $0.6^{\circ} \mathrm{C}$ on cloudy, calm 


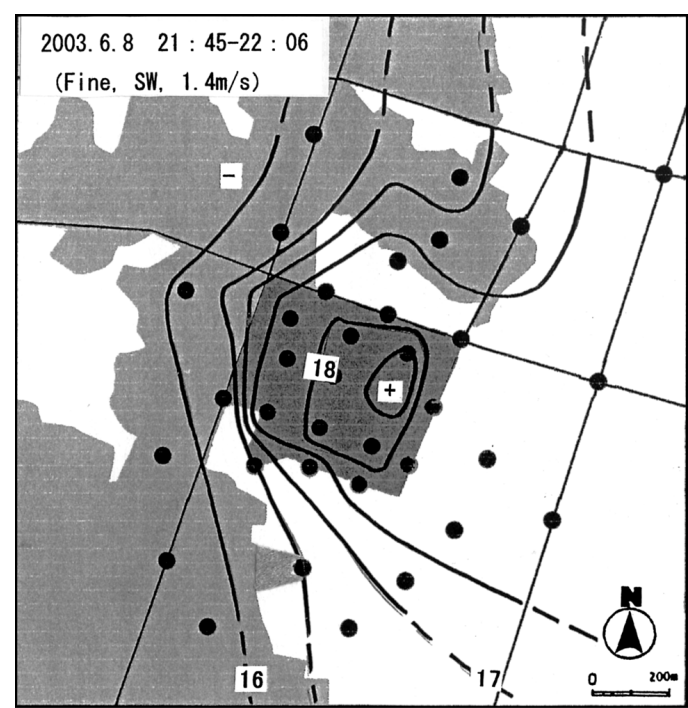

\begin{tabular}{|l|l|c|}
\hline High building area & Rural & \\
\hline Low building area & Observational site & O \\
\hline
\end{tabular}

Figure 4. Temperature distributions for a distinct heat island.

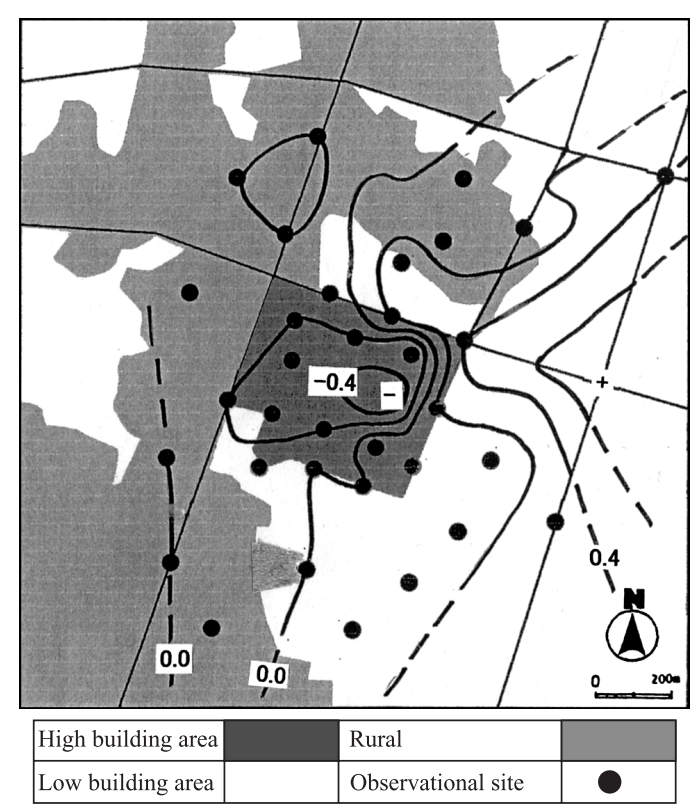

Figure 5. Mean temperature anomaly distribution during the day.

nights. These data suggest that construction materials with increased thermal admittance caused an urban heat island effect.

We next examined the dependence of heat island intensity on wind speed for 47 fine nights and 12 cloudy nights. The development of UHI varied by the season, because of the change of meteorological conditions and the other factors such as anthropogenic heat, precipitation, wind speed and cloud cover govern UHI (Oke 1973). Thus we took off data in days concerned in precipitation. And we divided the remaining days into fine days and cloudy days. Figure 6a shows the relationship
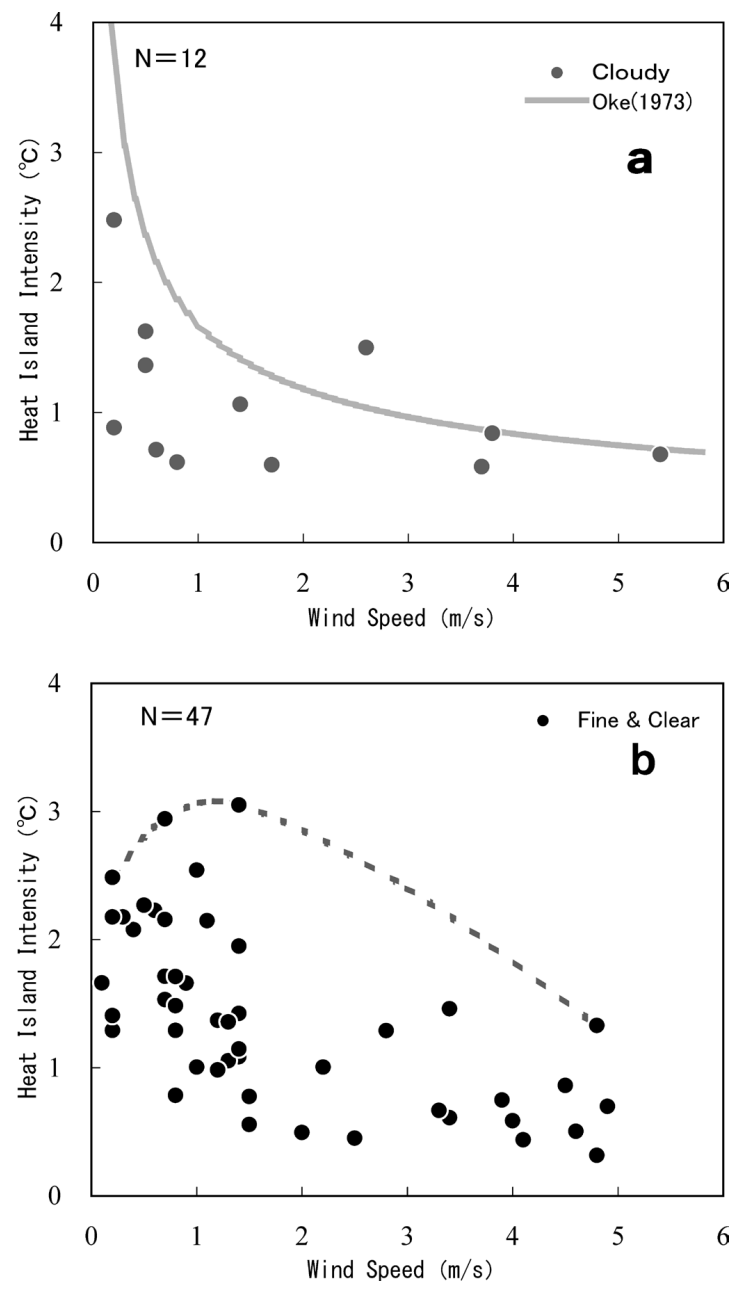

Figure 6. Relationship between wind speed and heat island intensity for fine and cloudy nights.

The bold solid line denotes the fitting line determined by Oke (1973) for a population of 2,000.

between nocturnal UHI intensity and wind speed for cloudy days. The bold solid line denotes the fitting line determined by Oke (1973) for a population of 2,000-the larger the wind speed, the smaller the upper limit of UHI intensity. It agreed with the fitting line by Oke (1973). The $\mathrm{UHI}$ intensity predicted by the fitting line for a population of 3,000 was $0.2^{\circ} \mathrm{C}$ higher for a wind speed of $1 \mathrm{~m} / \mathrm{s}, 0.1^{\circ} \mathrm{C}$ higher for a $2 \mathrm{~m} / \mathrm{s}$ wind speed, and $0.1^{\circ} \mathrm{C}$ higher for a $3 \mathrm{~m} / \mathrm{s}$ wind speed than that for a population of 2,000.

Figure $6 \mathrm{~b}$ illustrates the relationship between nocturnal UHI intensity and wind speed on fine days. The dotted line denotes the upper limit of UHI intensity, which means the optimal condition in which the factors, except for wind speed, act on heat island formation. As the wind speed increased, UHI intensity decreased. However, the upper limit did not simply become small, and reached a maximum at a wind speed of $1.4 \mathrm{~m} / \mathrm{s}$. This result agreed with that found by Sakakibara and Mieda (2002). The maximum wind speed in Sakakibara and Mieda's (2002) study was larger than that in this study; they had also 

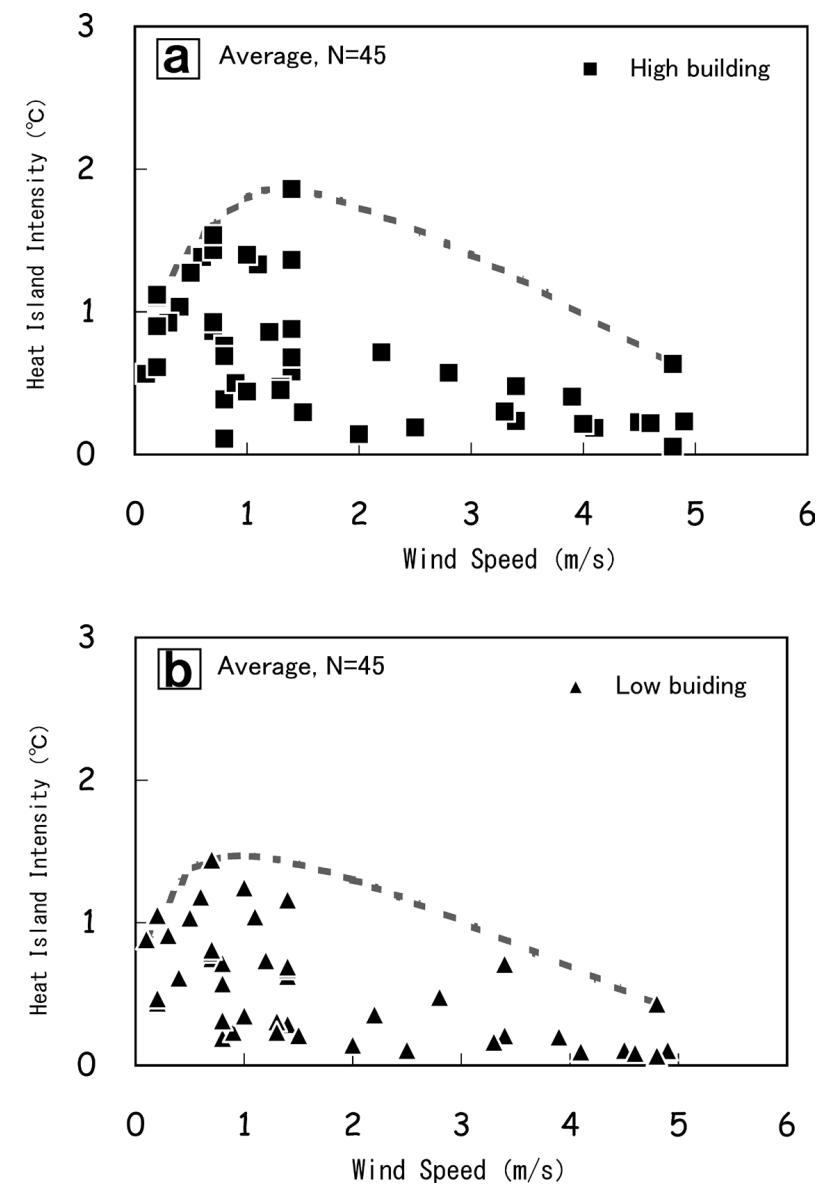

Figure 7. Relationship between wind speed and the urban-rural temperature difference for high and low building areas.

The dotted line denotes the upper limit of the urbanrural temperature difference.

examined an area with a larger urban population of 200,000 .

Figure 7 shows the relationship of the urban-rural temperature difference and wind speed for 45 fine nights. We selected points $22-30$ as the high building area, points 5 and 7-9 as the low building area, and points 11-17, 34 , and 35 as the rural area and calculated the average temperature in each area. The dotted line denotes the upper limit of the urban-rural temperature difference, which increased until a certain wind speed and then gradually declined as the wind speed increased. The upper limit for the high building area occurred at a wind speed of $1.4 \mathrm{~m} / \mathrm{s}$ and that for the low building area occurred at a wind speed of $0.7 \mathrm{~m} / \mathrm{s}$.

\section{Discussion}

Our results suggest that building height plays an important role in nocturnal heat island formation. We paid attention to differences in urban canopy indices between high and low building areas. We selected points

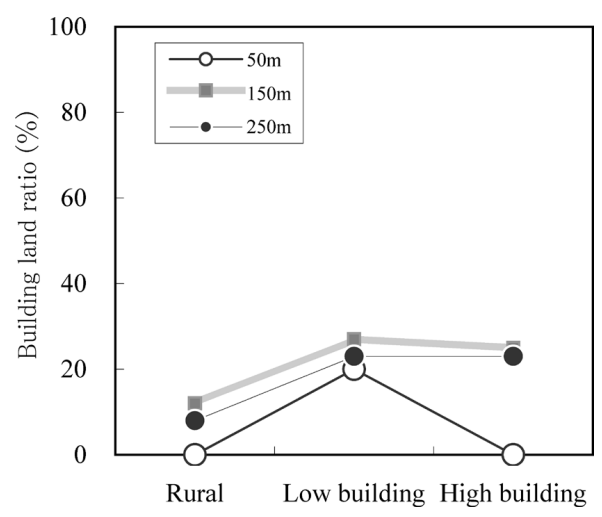

Figure 8. Building land ratios for rural, low building, and high building areas.

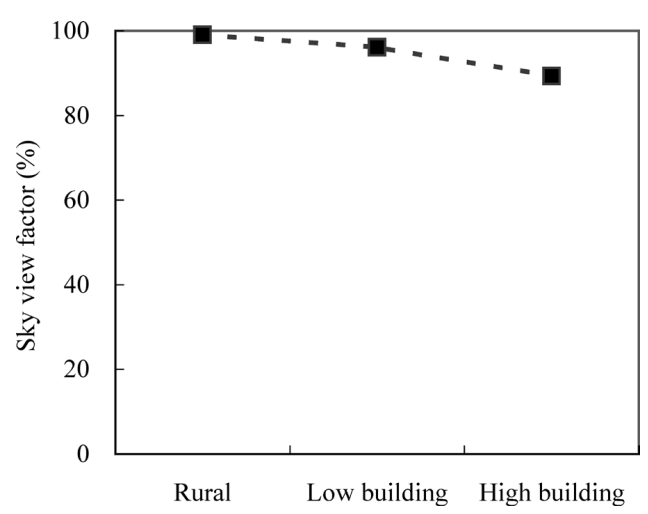

Figure 9. Sky-view factors for rural, low building, and high building areas.

22-30 as representative of a high building area, point 5, 7-9 for the low building area, and point 11-17, 34, 35 for the rural area as decided previously. We used the vegetation index, building/land ratio, floor-area ratio, and SVF as the urban canopy indices.

The building/land ratio also varied with the size of the range (Figure 8). However, building/land ratios for a square with 250 -m-long sides was nearly the same as that for a block with $150 \mathrm{~m}$ long sides. The average values for lengths of 150 and $250 \mathrm{~m}$ for the high building area were similar to those for the low building area but longer than those of the rural area. The SVF and vegetation indices of the high building area were the largest of the three areas (Figures 9 and 10); however, the difference among the areas was small (under 20\%). Remarkably, there was also little difference in the SVF, and values of SVF exceeded 0.8 . This result likely reflects city planning in the Imai housing estate, which places wide roads with large green spaces among the high buildings. Scale model experiments by Oke (1981) showed that canyon geometry did not affect heat island formation if the SVF were large (i.e., $80-100 \%$ ). Notably, there was also little difference in the building/land ratio between the high and low building 


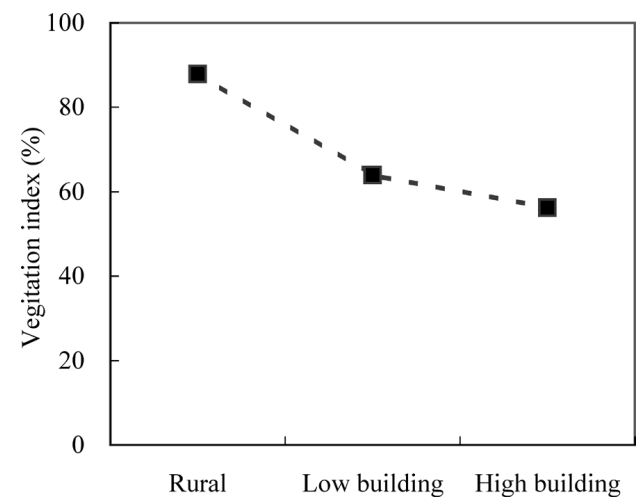

Figure 10. Vegetation indices for rural, low building, and high building areas.

areas.

A distinct change in urban canopy indices due to high buildings appeared in the floor-area ratio (Figure 11). It may be related to the increase of anthropogenic heat and roughness which lead to the mixing of urban atmosphere.

Next, we discuss cool island formation in the high building area in daytime. A cool island was not observed in the daytime temperature distributions for Obuse Town, Nagano Prefecture, Japan (Sakakibara 1999), where low buildings of two to three floors dominated the urban landscape. However, a cool island was found in the Imai housing estate, dominated by high buildings. The daytime cool island can be explained as follows: high buildings kept the area shaded longer, and the temperature increase in the urban area was small due to the large heat capacity of the buildings.

The SVF was also related to the effect of sun screening, and the floor-area ratio was involved with the heat capacity. Because differences in the SVF were small and those in the floor-area ratio were large, the cause of a daytime cool island may not be screening of the sun by buildings but rather the large heat capacity of high buildings. This result disagrees with that of Sugimoto and Kondo (1994).

Here, we discuss a feature of the nocturnal heat island by examining urban canopy indices. As the wind speed increased, the upper limit of UHI intensity did not simply become smaller; maximum value occurred at specific wind speeds. The maximum value for the high building area was larger than that for the low building area. Similarly, the wind speed for the high building area at which the maximum attenuation value occurred, was larger than that for the low building area. This result may reflect mechanical mixing of the urban atmosphere by the rough urban surface. The UHI intensity upper limit was regarded as the point in which factors, except the wind speed factor, acted ideally in creating the UHI

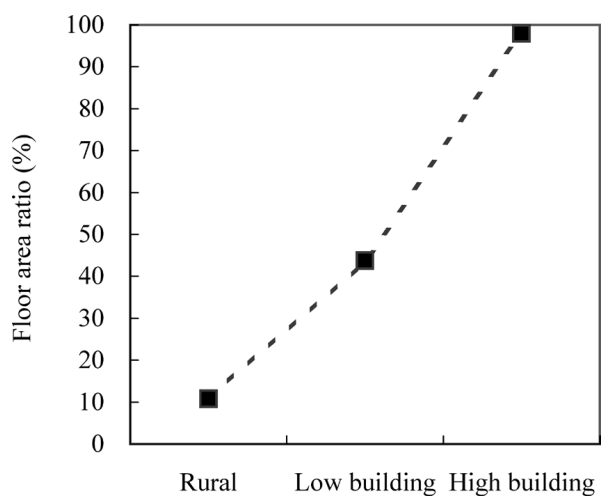

Figure 11. Floor-area ratios for rural, low building, and high building areas.

intensity. In this process, radiative cooling increases, the inversion layer develops, and the surface cools well during calm, fine nights, especially in rural areas. When the wind speed becomes high, the air on the ground generally mixes with air at higher levels. Even under weak wind conditions, the urban air on the ground mixes with warmer air above the urban surface because of the greater roughness in urban areas. Because cooling of the urban surface becomes small, a heat island can develop. When the wind speed increases still further, the inversion layer in rural areas is broken, and the UHI intensity declines. Consequently the maximum UHI intensity is considered to occur at a certain wind speed. The mixing depth for the high building area is also considered to be higher than that in a low building area, because the higher the building, the more the energy required for mixing. The energy needed may depend on the wind speed. The large roughness values in high building areas and with certain wind speeds thus gives rise to the nocturnal heat island formation.

Otherwise heat island intensity decreased as the winds became strong judging from the scatter diagram of wind speed and nocturnal UHI intensity roughly (Figures 6, 7) speaking. This suggests that nocturnal UHI is caused by anthropogenic heat, heat storage and so on, but the effect of mechanical mixing added to the cause of UHI formation when UHI appears remarkably.

\section{Conclusions}

The effect of the buildings in an urban area on UHI is studied with field observation in a high building area and a low building area. Both building areas showed little difference in SVF, vegetation index, and building/ land ratio values. This was brought about because of the regulation for the right to sunshine and the construction standard for large scale new town development. On the 
other hand, the floor-area ratio in the high building area was much larger than those in the low building area. Both high and low building areas were warmer than the rural area at night. But a cool island appeared only in the high building area in the daytime. It was suggested that this is due to larger heat capacity in the high building area. The maximum nocturnal UHI intensity occurred not at a calm condition but at the wind speed of about $1 \mathrm{~m} / \mathrm{s}$. In addition the wind speed in the high building area was higher than that in the low building area. The results suggest nocturnal UHI is raised by the mechanical mixing of the urban atmosphere and anthropogenic heat emission. The estimation of anthropogenic heat emission and the observation of vertical temperature/wind profile in and above an urban canopy layer and rural areas are the key to further clarify the cause of UHI.

\section{Acknowledgements}

This research was supported in part by the Grantsin-Aid for Scientific Research program of the Ministry of Education, Culture, Sports, Science and Technology of Japan. We thank Mr. HAMADA of the Nagano Environmental Conservation Research Institute for his helpful advice and assistance with this manuscript.

\section{References}

Fukuoka, Y. 1983. Physical climatological discussion on causal factors of urban temperature. Memories of the Faculty of Integrated Arts and Sciences, Hiroshima University IV 8: 157178.

Itoh, K. 1976. Nisshokankeizuhyo no mikata tsukaikata (A way of watching and using of charts about sunlight). Ohmsya: Tokyo. (J)

Kusaka, H. and Kimura, F. 2004a. Coupling a single-layer urban canopy model with a simple atmospheric model: Impact on urban heat island simulation for an idealized case. J. Meteor. Soc. Japan 82: 67-80.
Kusaka, H. and Kimura, F. 2004b. Thermal effects of urban canyon structure on the nocturnal heat island: Numerical experiment using a mesoscale model coupled with urban canopy model. J. Appl. Meteor. 43: 1899-1910.

Martilli, A. 2002. Numerical study of a boundary layer structure: Sensitivity to wind speed, urban morphology, and rural soil moisture. J. Appl. Meteor. 41: 1247-1266.

Ohashi, Y., Genchi, Y., Kondo, H., Kikegawa, Y. and Hirano, Y. 2007. Influence of air-conditioning waste heat on air temperature in Tokyo during summer: Numerical experiments using an urban canopy model coupled with a building energy model. J. Appl. Meteor. 46: 66-81.

Oke, T. R. 1973. City size and the urban heat island. Atmos. Environ. 7: 769-779.

Oke, T. R. 1981. Canyon geometry and the nocturnal urban heat island: Comparison of scale model and field observations. J. Climatol. 1: 237-245.

Oke, T. R. 1987. Boundary layer climates. Methuen: New York.

Park, H. 1987. Variations on the urban heat island intensity affected by geographical environments. Environ. Res. Ctr. Pap. 11: $1-79$.

Sahashi, K. 1983. Errors in the air temperature observation by traveling method with the automobiles-effects of the automobiles. Tenki 30: 509-514. (J)

Sakakibara, Y. 1999. The relationship between heat island intensity and rural land coverage in Obuse, Nagano. Tenki 56: 567-575. (JE)

Sakakibara, Y. and Mieda, A. 2002. Causes of nocturnal heat island and the difference between heat island intensity on fine days and cloudy days. Tenki 49: 533-540. (JE)

Sugimoto, S. and Kondo, J. 1994. An observational study of heat island and diurnal variation of surface temperature of the various grounds. Tenki 41: 541-544. (J)

Tokairin, T., Kondo, H., Yoshikado, H., Genchi, Y., Ihara, T., Kikegawa, Y., Hirano, Y. and Asahi, K. 2006. Numerical study on the effect of buildings on temperature variation in urban and suburban areas in Tokyo. J. Meteor. Soc. Japan 84: 921937.

Uno, I., Wakamatsu, S., Ueda, H. and Nakamura, A. 1988. An observational study of the structure of the nocturnal urban boundary layer. Bound. Layer Meteor. 45: 59-82.

( $\mathrm{J})$ : written in Japanese

(JE): written in Japanese with English Abstract 